\title{
Growth variations in the bivalve Mya truncata: a tool to trace changes in the Frisian Front macrofauna (southern North Sea)?
}

Received: 12 November 2002 / Accepted: 17 April 2003 / Published online: 27 May 2003

(C) Springer-Verlag and AWI 2003

\begin{abstract}
Annual monitoring of the benthic fauna living at the Frisian Front (southern North Sea) has shown a tenfold decrease in the dominant brittlestar Amphiura filiformis in 1993-1995. In search of evidence that this decline was caused by a change in benthic food supply, we analysed variations in the shell growth of the bivalve Mya truncata from the Frisian Front during the period of interest. For this purpose, the widths of the internal growth bands in the chondrophore of $M$. truncata were standardised and assigned to calendar years. Averaging the yearly band width in the period 1985-2000 among 25 individuals revealed low growth rates in 1986 and 1992. Growth of M. truncata quickly recovered after 1992, while A. filiformis densities remained at low levels. Moreover, the 1986 dip in M. truncata growth had no equivalent in A. filiformis density. We conclude that there is no direct coupling between fluctuations in density of $A$. filiformis and variations in growth of $M$. truncata. The data we collected during this study on the size and spatial distribution of $M$. truncata are discussed in the light of plans for the protection and conservation of long-lived benthic organisms in the North Sea.
\end{abstract}

Keywords Growth $\cdot$ Bivalve $\cdot$ North Sea benthos

\section{Introduction}

The southern North Sea is one of the world's most exploited shelf seas. A number of activities, such as the intensive beam trawl fishery and oil and gas exploitation, and river inputs form potential threats to the ecosystem health and biodiversity. Because of concern about degradation and impoverishment of the benthic ecosystem,

Communicated by E. Rachor

T. Amaro $(\bowtie) \cdot$ G. Duineveld · M. Bergman · R. Witbaard

Royal Netherlands Institute for Sea Research,

P.O. Box 59, 1790 AB, Den Burg, The Netherlands

e-mail: amaro@nioz.nl

Tel.: +31-222-369300

Fax: +31-222-319674 the Ministry of Public Works and Transport initiated a macrobenthos monitoring programme in the Dutch continental sector, which started in the early 1990s. Results of this programme have been published in a series of annual reports (see references in Daan and Mulder 2001).

One of the monitoring stations is situated in the Frisian Front (Fig. 1), which separates the summer-stratified watermasses in the Oyster Ground and the permanently mixed waters in the Southern Bight (Tomczak and Goedecke 1964). Since the early 1980s this frontal zone has been the subject of a series of studies, the earliest of which described the enrichment of benthic fauna in the vicinity of the front and the conspicuous zonation in feeding types (Creutzberg et al. 1984). Subsequent studies showed that, during a large part of the year, the water column over the enriched zone was characterised by elevated chlorophyll- $a$ concentrations (Creutzberg 1985; Cramer 1991). The locally enhanced deposition of fresh phytodetritus was seen as explanation for the high biomass and high densities, notably of interface-feeding organisms like the dominant brittle star Amphiura filiformis.

A recent comparison of the macrobenthic fauna living in the Frisian Front area between 1980 and 2000 showed that conspicuous numerical shifts have occurred among the keystone species, in particular A. filiformis and ghost shrimps (Callianassa, Upogebia) (Amaro et al., in preparation). A. filiformis populations often can be stable for long periods (O'Connor et al. 1983). In the case of the Frisian Front population, a 12-year period with stable densities of $\sim 1,500$ ind $\mathrm{m}^{-2}$ (Duineveld and Van Noort 1986) was followed by a period of decrease starting in 1993 and continuing until 1995, whereafter numbers have remained more or less constant at a level of one order of magnitude lower (details in Amaro et al. in prep). One hypothesis for the observed shift is a change in food availability. As interface and suspension-feeder A. filiformis is directly dependent on a vertical supply of food particles and thus primary production in contrast to subsurface feeders can sustain on more refractory carbon present in deeper sediment layers. However, we do not 
have long term data on the benthic food supply at the Frisian Front, or on primary production.

One way to reconstruct whether the benthic food supply changed in the period when A. filiformis declined is to study the growth records deposited in the shells of suspension-feeding bivalves living at the Frisian Front. By analogy with tree rings, various authors have used growth band patterns in skeletons of bivalves and corals to reconstruct chronological records of marine environmental changes (e.g. Lutz 1976; Brousseau and Baglivo 1987; Jones et al. 1989; Nakaoka 1994; Witbaard et al. 1997). We selected Mya truncata for this purpose because it can reach a maximum age of 40 years and because adults live deep in the sediment where they are protected from direct fishing disturbance (Hewitt and Dale 1984). Arctica islandica, which is also part of the local community, has a more complicated growth band pattern because it can reach a much older age (over 100 years) and, moreover, is more exposed to damage and disturbance by beam trawl fishery (Witbaard and Klein 1994).

While analysing the growth of $M$. truncata from the Frisian Front we specifically searched for a common pattern among individuals during the period when $A$. filiformis densities drastically decreased. We discuss our findings on $M$. truncata in the light of available literature data on environmental changes in the southern North Sea during the period of interest. In addition to the growth data on $M$. truncata we report new information on its distribution in the Dutch sector.

\section{Methods}

Site description

The study area is located in the southern North Sea and is characterised by a south to north increase in depth $(20-50 \mathrm{~m})$ and a decrease of maximum tidal velocity (1.8-0.7 knots). These factors contribute to a gradual south to north transition from coarse to fine sediment and to the occurrence of mud in the northern part of the area. At approximately $53^{\circ} 30^{\prime} \mathrm{N}$, current velocities drop below a threshold value allowing (semi-)permanent deposition of mud and detritus, as well as the generation of summer stratification north of this latitude. A tidal front separates the mixed waters in the south from the summer-stratified waters in the north (Creutzberg et al. 1984). Just north of this boundary, between the $30 \mathrm{~m}$ and $40 \mathrm{~m}$ isobaths, there is a muddy zone (Frisian Front in Fig. 1) with high sediment concentrations of organic carbon $(0.4 \%)$ and algae pigments, and a high macrofauna biomass ( $\left.25 \mathrm{~g} \mathrm{AFDW} \mathrm{m}^{-2}\right)$. This enrichment is probably related to the persistent chlorophyll- $a$ maximum in the vicinity of the $30 \mathrm{~m}$ isobath (Creutzberg 1985).

\section{Species description}

M. truncata has a wide, circumboreal distribution. It is a key species in food webs in arctic habitats (Welch et al. 1992). In Europe, $M$. truncata is common along the entire coastline of the United Kingdom and Ireland, and down further south to Biscay (Willmann 1989; Ballerstedt 2001). According to literature records, $M$. truncata does not have a special preference for sediment type. It has been found in sand, sandy mud and gravel from the lower shore down to about $70 \mathrm{~m}$ depth.

\section{Sampling}

Living specimens of $M$. truncata $(n=96)$ were collected between June and December 2000 at the Frisian Front in a small area north of the $30 \mathrm{~m}$ isobath in the vicinity of position $53^{\circ} 48^{\prime} \mathrm{N} 4^{\circ} 30^{\prime} \mathrm{E}$. For collection, we used the Triple-D dredge (Bergman and van Santbrink 1994) because the abundance of M. truncata is too low
Fig. 1 Map of the southern North Sea showing the 30 and $40 \mathrm{~m}$ isobaths, and the percentages of mud (particles $<64 \mu \mathrm{m}$ ) in greyscale. The mud patch marked Frisian Front is the area where the enriched benthic zone has been found (see text). Inset shows the study area in the North Sea

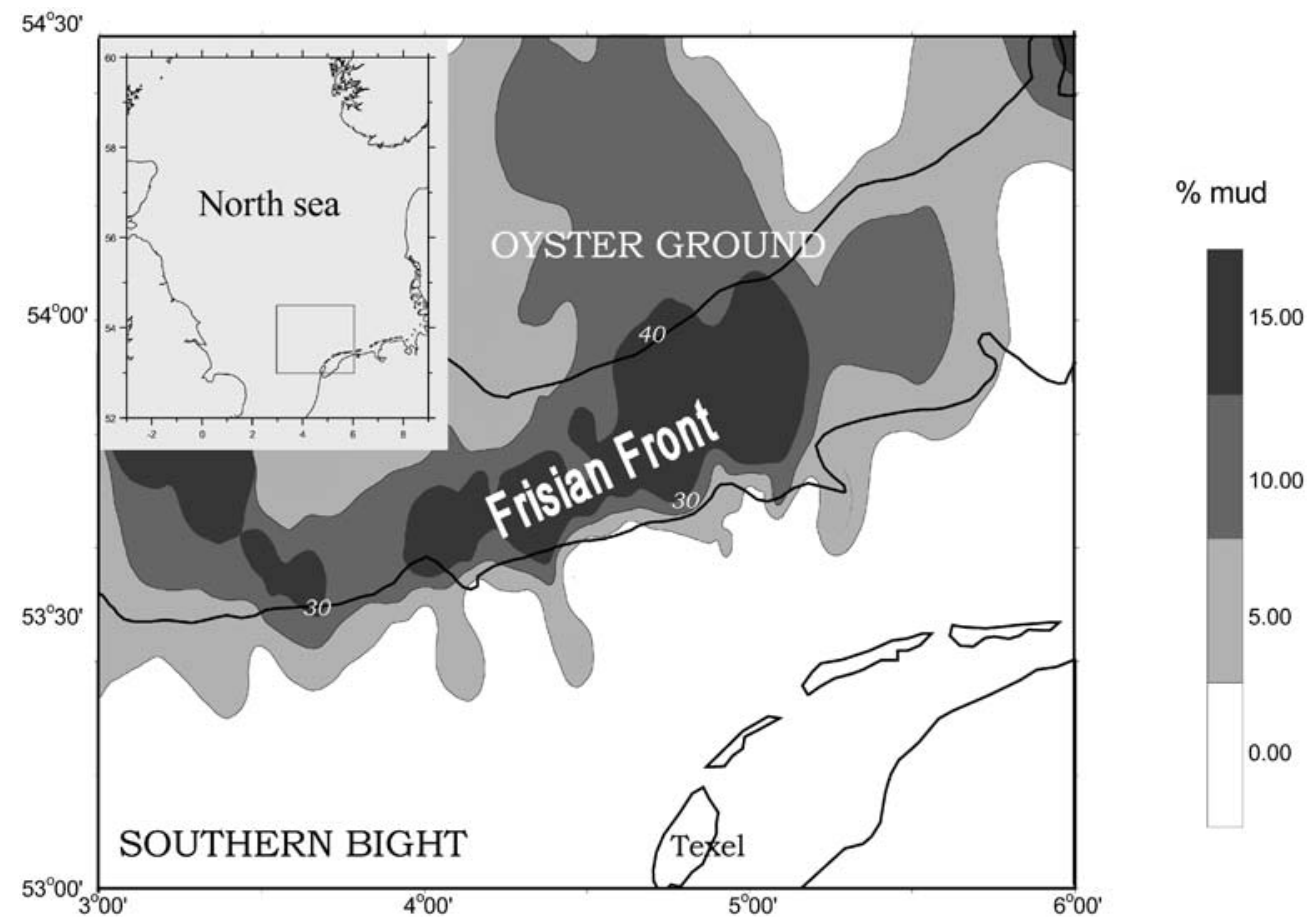




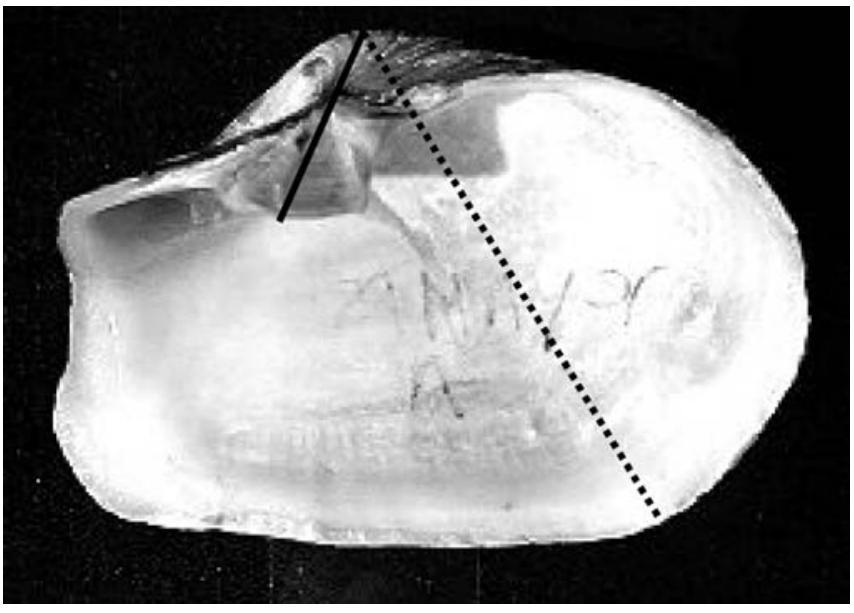

Fig. 2 Photograph of the inside of a left valve of Mya truncata with chondrophore. The solid line through the chondrophore is the direction along which the shell was sawn. The dotted line is the extension of this line along the exterior of the shell. The surface enclosed by these two lines is the actual plane of sectioning

to allow efficient sampling with either a boxcorer or van Veen grab. The Triple-D had a net with a mesh size of $1.4 \mathrm{~cm}$ (stretched), and its digging depth was $18 \mathrm{~cm}$. The length of the hauls was $80 \mathrm{~m}$, which is equivalent to a total surface of $16 \mathrm{~m}^{2}$. Bivalves with a length $>10 \mathrm{~mm}$ are retained by the dredge. Intact and damaged specimens, as well as cut-off siphons were counted for density estimates. A total of 25 intact shells from this collection were selected for age and growth analysis. These specimens were without any shell damage or visible growth disruption in the valve or chondrophore.

\section{Chronology of growth variations}

Internal growth bands were measured in acetate peels made of cross sections of the left valve in accordance with MacDonald and Thomas (1980) and Hewitt and Dale (1984) who studied growth in the related Mya arenaria and arctic $M$. truncata, respectively. We used the growth band pattern in the chondrophore since this part of the Mya shell yields the most distinct bands. Left-hand valves were embedded in epoxy resin (Polypox, THV 500, harder 125) and sectioned with a diamond saw along a line through the hinge tooth to the point of maximum extension (Fig. 2). The cross-sections were ground, polished and etched, and the micro-relief transferred to an acetate sheet (Ropes 1985). Each acetate peel was photographed in parts with a digital camera mounted on a microscope. A composite image of the peel was prepared in Microsoft PowerPoint and printed as hard copy. The widths of the growth bands were measured on the hard copy with a calliper and converted to actual shell dimensions. As all shells were collected alive in autumn 2000, each growth band could be assigned to the specific year in which it was formed by counting back from the shell margin. Band widths in the composite image were measured independently by two people. Disagreement between the two measurements was invariably due to either growth bands delimited by several closely grouped lines of which it was difficult to assess which one represented the annual growth stop, or progressively narrowing bands near the edge of the chondrophore making it difficult to distinguish one band from another. In such cases both readings were retained for later analysis (see below).

To be able to compare growth in a specific year in individuals of different ages, growth (band widths) had to be standardised because the growth rate of $M$. truncata, as for most organisms, declines with age. This ontogenetic growth trend was removed by substituting absolute band widths by an index of relative growth, viz. the log- transformed ratio between the observed and the expected band width (Cook et al. 1990). The expected width in a particular year was derived from a fitted growth model. To determine which growth model was most efficient in removing the ontogenetic trend in $M$. truncata, we tried the following five commonly used growth functions (see Sager and Sammler 1983):

Gompertz:

von Bertalanffy:

Janoschek:

Logistic:

Boltzman:

$$
\begin{aligned}
& L_{t}=L_{\infty} \mathrm{e}^{-\exp [-k(t-t 0)]} \\
& L_{t}=L_{\infty}\left[1-\mathrm{e}^{-k(t-t 0)}\right] \\
& L_{t}=L_{0}+\left(L_{\infty}-L_{0}\right)\left(1-\mathrm{e}^{\left.-k t^{\wedge} k^{*}\right)}\right. \\
& L_{t}=L_{\infty}+\left(L_{0}-L_{\infty}\right) /\left[1+\left(t / t_{0}\right)^{k}\right] \\
& L_{t}=L_{\infty}+\left(L_{\mathrm{a}}-L_{\infty}\right) /\left[1+\mathrm{e}^{(t-t 0) / k}\right]
\end{aligned}
$$

where $L_{t}$ is the size at time $t ; L_{0}$ is the size at $t=0 ; L_{\infty}$ is the maximum size; $k$ and $k^{*}$ determine the rate at which maximum size is approached; $L_{\mathrm{a}}$ is length at $t=t_{0}$. Our choice of a suitable growth function was only led by the best least squares fit and not by any inferences about the biological meaning of the models.

The series of index values was plotted using PAST32 software (SCIEM) in order to check the correspondence between replicate measurements of one shell and between different shells. Correspondence was calculated as "Gleichläufigkeit" (Schweingruber 1989), i.e. the number of similar growth rate changes in two measurement series expressed as a percentage of the total number of years that two series have in common. We used "Gleichläufigkeit" values to search for outliers and, in case of incongruous replicate readings, to decide which one fitted the overall pattern best.

\section{Results}

\section{Distribution and size of $M$. truncata}

The distribution of M. truncata in the Dutch Sector of the North Sea is shown in Fig. 3. So far it has only been found

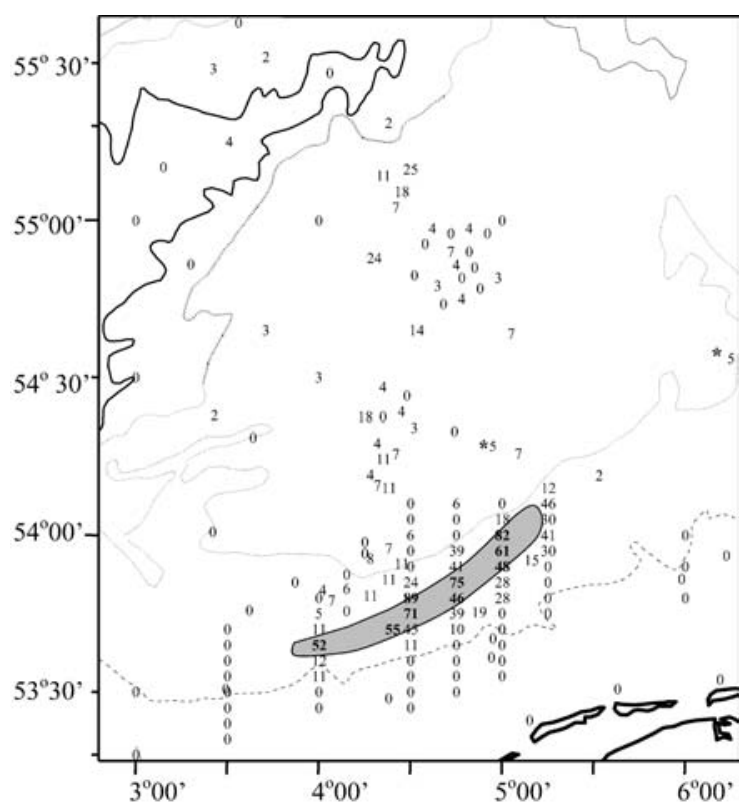

Fig. 3 Distribution and densities (ind $100 \mathrm{~m}^{-2}$ ) of $M$. truncata in the Oyster Ground (southern North Sea). The shaded area comprises the stations where relatively high abundances $(>50$ ind $100 \mathrm{~m}^{-2}$ ) of $M$. truncata were found. The star represents multiple samples in a small area 
in the Oyster Ground, i.e. north of $53^{\circ} 40^{\prime} \mathrm{N}$, which is the deeper part of the Dutch Sector (30-50 m water depth). The sediment in the Oyster Ground consists of muddy sand with the amount of mud $(<64 \mu \mathrm{m})$ varying between $5 \%$ and $25 \%$. The highest densities of M. truncata in our samples, viz. $>50$ ind $100 \mathrm{~m}^{-2}$, appear to be concentrated in a narrow band running SW to NE along the Frisian Front. This band more or less coincides with the highest percentages of mud (Pearson $r_{\text {mud-Mya }}=0.71, P<0.001$ ). $M$. truncata appears to be absent from the shallower $(<30 \mathrm{~m})$ Southern Bight where clean sandy sediments (mud $<5 \%$ ) and higher tidal current speeds prevail. Due to the combination of current speed and depth, the Southern Bight remains mixed throughout the year whereas the water column in the Oyster Ground becomes stratified during summer. As a consequence, the maximum bottom water temperatures in the Oyster Ground are lower than in the Southern Bight (Tomczak and Goedecke 1964).

Figure 4 shows the size frequency distribution of all $M$. truncata specimens caught $(n=162)$ with the Triple-D dredge in the Dutch Sector over the period 1998-2000. Remarkably, individuals $<50 \mathrm{~mm}$ have almost never been caught with the Triple-D in spite of the fact that bivalves $>10 \mathrm{~mm}$ are retained in the dredge (Bergman and van Santbrink 1994). The yearly monitoring of the benthic fauna in the Dutch continental sector (Daan and Mulder 2001) using a boxcorer and $1 \mathrm{~mm}$ sieve has also not yielded any $M$. truncata between 0.5 and $4 \mathrm{~cm}$ (R. Daan, personal communication).

\section{Growth bands}

Acetate peels of cross sections of the valve and chondrophore of $M$. truncata revealed distinct microgrowth bands composed of a dark line (growth stop) delimiting increments of variable width (Fig. 5). Given that the growth bands are formed annually, we estimated the ages of the 25 specimens studied to vary between 13 and 28 years (Fig. 6). After measuring the growth band widths in the chondrophore of each specimen, we made a plot of the cumulative chondrophore length versus age. By averaging the lengths at each age we obtained the curve shown in Fig. 7. This shows a more or less smooth transition from rapid growth to a phase of slow growth as is also found in arctic M. truncata (Hewitt and Dale 1984). The increase in the standard deviations of the mean with age in Fig. 7 is due to the decreasing number of data points and the increasing absolute size.

Of the five growth models used, Bolzman's growth function yielded the lowest sums of squares on average (Table 1) and, moreover, the residuals showed no consistent trend (Fig. 8). An example of Bolzman's function fitted to the cumulative chondrophore length of one M. truncata is given in Fig. 7. Using the fitted values, we calculated expected growth and subsequently the standardised index for each year. This ultimately gave 25 series of index values of variable length belonging to the 25 individuals. The ages in each series were then

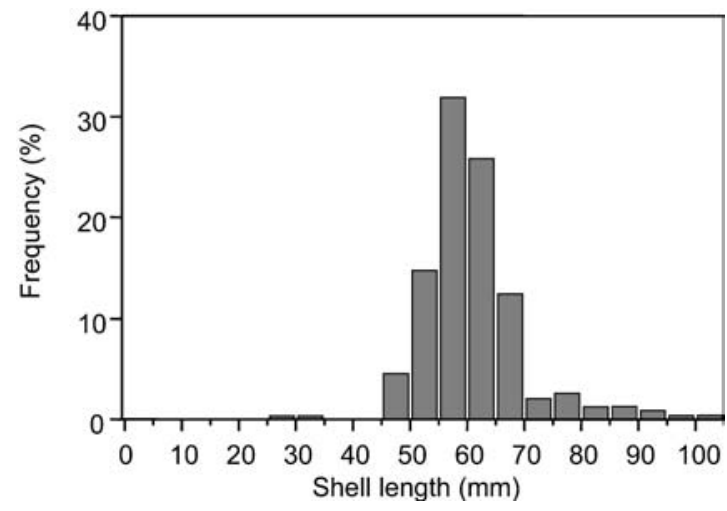

Fig. 4 Length frequency distributions of $M$. truncata collected during the period 1998-2000

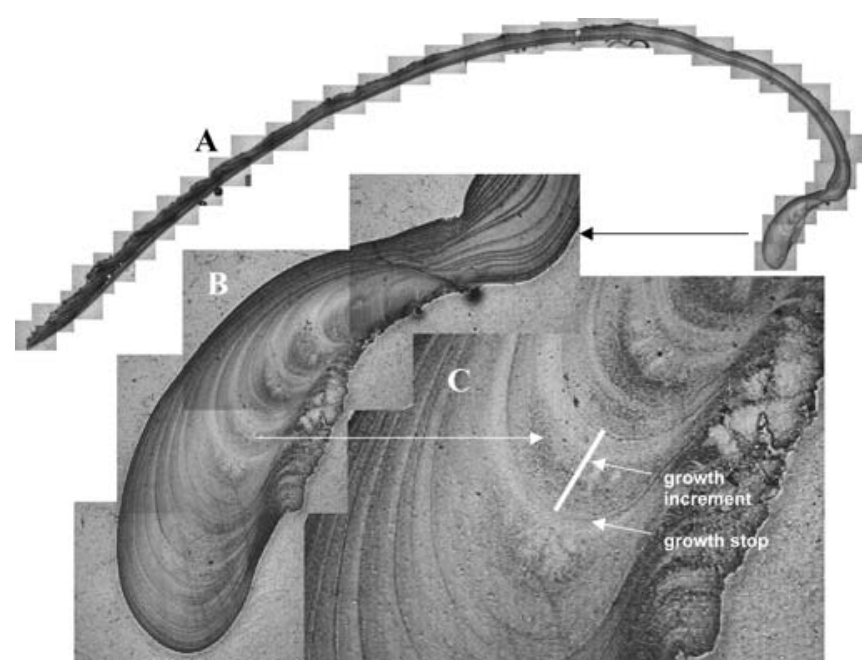

Fig. 5 A Composite image of an acetate peel of a cross section of a left valve of $M$. truncata. The distance from shell margin to chondrophore is $68.2 \mathrm{~mm}$. B Detail of chondrophore with growth band pattern. $\mathbf{C}$ Example of a growth band consisting of increment and stop. The scale bar in the increment measures $360 \mu \mathrm{m}$

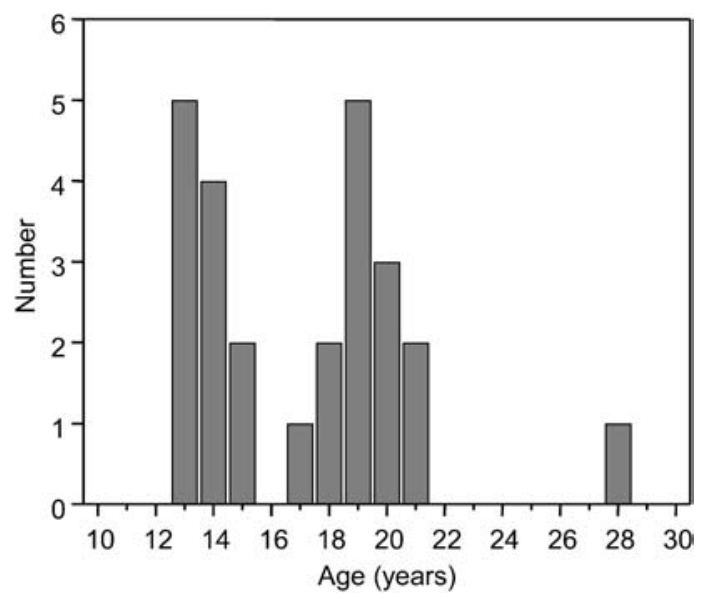

Fig. 6 Age distribution of the $25 M$. truncata used in this study 


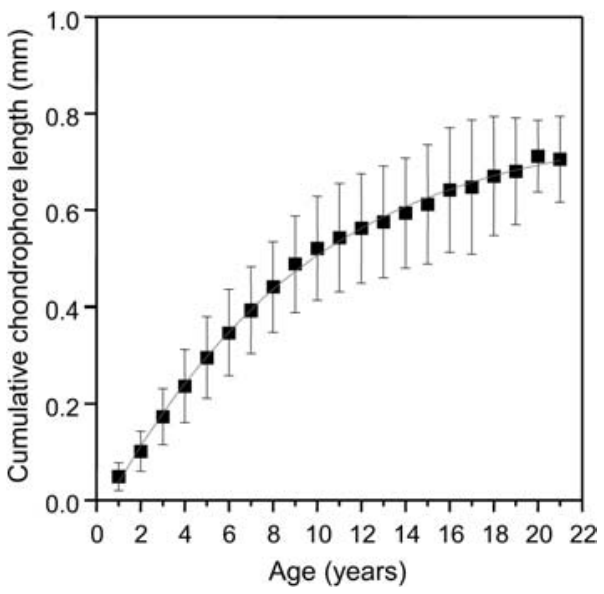

Fig. 7 Chondrophore length versus age in M. truncata. Means (solid squares) and SD (bars) are calculated from 25 series of cumulative band widths versus age. To illustrate the pattern, a line (Bolzman's function) was fitted through the means

Table 1 Mean and standard deviation (SD) of the residual sum of squares obtained after fitting five different models to the cumulative hinge growth of Mya truncata (see Fig. 8)

\begin{tabular}{lll}
\hline Growth model & Mean residuals & SD residuals \\
\hline Gompertz & 0.00461 & 0.00391 \\
Boltzman & 0.00322 & 0.00383 \\
Logistics & 0.00402 & 0.00401 \\
Bertalanffy & 0.00705 & 0.00886 \\
Janoschek & 0.00794 & 0.00922 \\
\hline
\end{tabular}

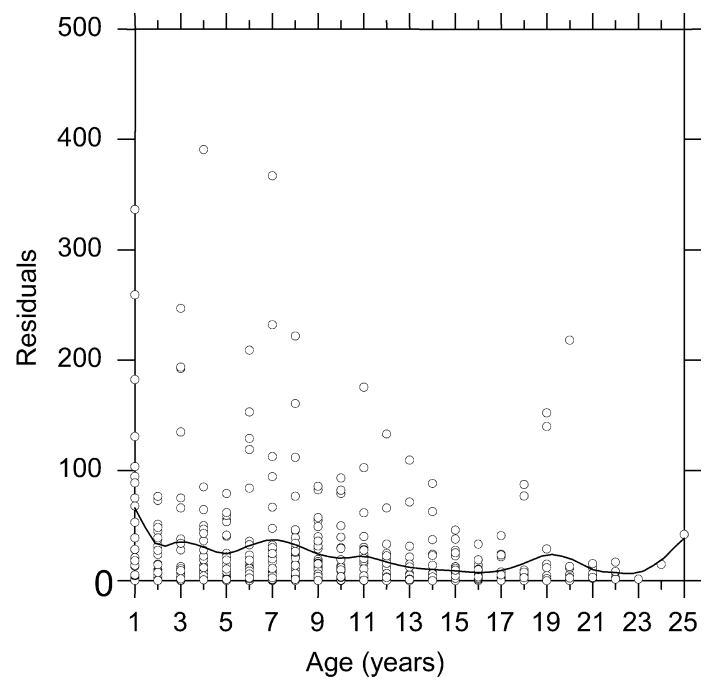

Fig. 8 Plot of residuals versus age. The residuals represent the squared differences between the measured size at age and the size at age predicted by the Bolzman's model

substituted with actual years, and averages and standard deviations of the index values were calculated for each particular year. We present these values for the years 1985-2000 since this period covers the years of the

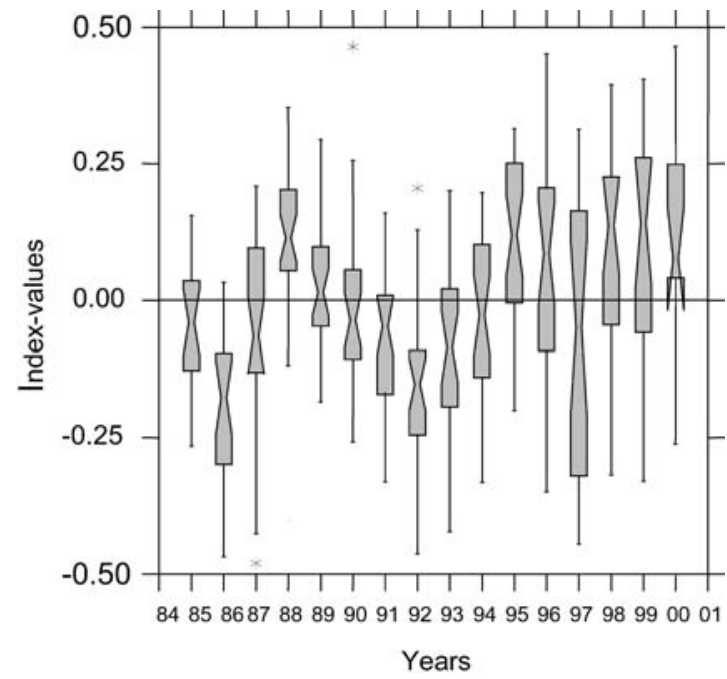

Fig. 9 Notched Box plot of the index values over the period 1985 2000. Non-overlapping notches denote significant differences between means. The stars represent outliers

decline of A. filiformis and, moreover, values before 1985 were based on a limited number of individuals $(<15)$.

Figure 9 shows a notched box plot (McGill et al. 1978) of the index values of the 25 M. truncata between 1985 and 2000. In 1988 and 1989, index values were positive, i.e. growth was higher than expected with a tendency to decrease. In 1990, growth dropped below expected values and remained so until 1994. The largest negative deviation was found in 1992. The non-overlapping notches around the box plots in Fig. 9 show that growth in 1992 was significantly lower than in 1988, and this was confirmed by a $t$-test $(t=-5.679, d f=54.9, P<0.0001)$. The same is true for the difference between 1989 and 1992 $(t=-5.164, d f=48.7, P<0.0001)$. It is worth noting that from 1992 onwards growth rates increased again, attaining above expected values by the mid 1990s. In subsequent years the variation became too large to allow any meaningful statistical comparison.

\section{Discussion}

The reason for undertaking this study on the growth of $M$. truncata at the Frisian Front was the dramatic decline in the dominant ophiuroid A. filiformis in 1993. The dense $A$. filifornis zone that was present throughout the period 1980-1992 was regarded as typical for-and coupled with-the organic enrichment of the Frisian Front. The enrichment of the frontal zone has been demonstrated in various studies in the form of high sediment respiration rates, elevated chlorophyll- $a$ levels in the water column and sediment, and high biomass values of many taxa, viz. invertebrates, demersal fish, pelagic organisms, hyperbenthos, seabirds (Creutzberg 1985; Cramer 1991; de Gee et al. 1991). A similar association between enhanced input from a pelagic front and the abundance of A. filiformis has been found in the Skagerrak (Josefson and Conley 1997), 
while on the west coast of Ireland high A. filiformis densities are associated with a gyre concentrating food (O’Connor et al. 1983).

In view of the close link between dense A. filiformis occurrences and enhanced food input, the first hypothesis to explain the A. filiformis crash at the Frisian Front involved benthic food conditions. Direct measurement of benthic food supply at offshore turbulent sites requires scarce resources, i.e. ship time and special instruments (Duineveld and Boon 2002). Growth records deposited in bivalve shells like $M$. truncata can offer a simple alternative as the organisms integrate conditions over relevant timescales and, moreover, allow retrospective analyses (Richardson 2001).

The standardised growth record of $M$. truncata at the Frisian Front (Fig. 9) shows that, during the period 19911993, growth was below expected values, with 1992 being the year with the lowest average growth index. A. filiformis densities were still at a normal high level in spring $1992\left(\sim 1,500\right.$ ind $\left.\mathrm{m}^{-2}\right)$, but in the subsequent campaign of spring 1993 densities were below 1,000 ind $\mathrm{m}^{-2}$ for the first time in a decade (details in Amaro et al., in preparation). A. filiformis density continued to decrease in 1994 and remained at a low level in subsequent years whereas, the growth index of $M$. truncata showed an increase again from 1995 onwards (Fig. 9). So, at first sight, there seems to be no direct correlation between the two events. Hypothetically, however, enhanced mortality of A. filiformis in 1993 could have been caused by a depressed food supply in preceding year(s) deteriorating the condition of the brittlestars. Nilsson (1999) showed that arm regeneration in A. filiformis depends on food supply. With the many A. filiformis in the Frisian Front population having one or more arms cropped by flatfish (Duineveld and Van Noort 1986), food shortage could lead to sustained loss of function and ultimately increased mortality. Assuming that the dip in M. truncata growth in 1992 represents a food shortage, it remains questionable whether the shortage would have been severe enough to have such a dramatic effect on A. filiformis. Figure 9 shows that the growth record of $M$. truncata contains another dip in 1986 which is as deep as the 1992 one. However, A. filiformis numbers at the Frisian Front remained high throughout the 1980s. Given this somewhat inconclusive evidence from $M$. truncata, we have looked for additional data which in one way or another are indicative for the benthic food supply in the period of interest.

Long-term CPR data show that in the late 1980s phytoplankton biomass increased above the long term mean and has remained high since then, notably in winter (Edwards et al. 2002). Time-series on macrofauna biomass in the North Sea also yield no evidence of a marked drop in the early 1990s. Kröncke et al (1998) reported an increase in macrofauna biomass off the coast of Norderney in 1988 and persistently high levels in the following years. Daan and Mulder (2001) also did not find any marked change in macrofauna biomass in the major subregions of the southern North Sea in the period
1990-2000. In summary, the lack of compelling evidence for a large scale change in food availability in the southern North Sea points at a local factor being responsible for the A. filiformis crash at the front. We do not rule out, however, that food shortage has played a role, taking into account the steep gradient in environmental conditions at the Frisian Front. Forthcoming growth analysis of other suspension feeders, e.g. A. islandica and Dosina lupinus, might produce more solid answers.

Besides a historical growth record of M. truncata, our study yielded new data on the spatial and size distribution of this bivalve species in the southern North Sea. The distribution of $M$. truncata in the southern North Sea appears to be concentrated round the Oyster Ground (Fig. 3). According to literature, M. truncata is a boreal species without a distinct sediment preference. Hence, we suppose that its distribution pattern in the southern North Sea is related to maximum temperatures which are lower in the Oyster Ground than in the Southern Bight due to stratification and depth. This does not explain the band of high densities at the muddiest sites of the Frisian Front in Fig. 3. If sediment is not a relevant factor, the coincidence of highest $M$. truncata densities and mud percentages could point to a common hydrological factor, i.e. optimal conditions for deposition of both fine particles and of larvae, to locally favourable conditions for survival, or to a combination of both.

Another remarkable finding of our study is the skewed size distribution of the M.truncata that we have collected, and specifically the lack of juveniles in the $1-4 \mathrm{~cm}$ size class. The cause for this skew is unknown, but could be infrequent larval supply and/or high juvenile mortality. It is striking that the other large and long-living bivalve in the southern North Sea, A. islandica, displays the same type of size distribution (Witbaard and Bergman 2003). Comparing different North Sea A. islandica populations, these authors state that the skewed size distribution of $A$. islandica at the Frisian Front is atypical, and probably due to bottom trawling. They further argue that the Frisian Front stock is unlikely to form a sustainable population if fishing pressure continues. We could not find data on $M$. truncata from less heavily fished regions to compare with, but we do point to the possibility of fishing being responsible for the peculiar size structure, since juvenile $M$. truncata are more likely to be exposed to trawl damage than deeply buried, older animals. In any case, the low adult density resulting from the presently poor recruitment rate may form an obstacle for successful fertilisation (Metaxas et al. 2002) and thus self-sustenance. Therefore, the occurrence of M. truncata, and possibly A. islandica as well, at the Frisian Front will, or has already, become dependent on the influx of pelagic larvae transported with UK coastal water.

Large and long-lived benthic organisms such as $A$. islandica and $M$. truncata are frequently mentioned in the context of conservation of the southern North Sea biodiversity, and as Ecological Quality ObjectivesEcoQOs (Bisseling et al. 2001). Success of measures to 
protect or restore these long-lived benthic species depends on a proper insight into their population dynamics, especially its juvenile phase. The scarcity of relevant data on $M$. truncata and $A$. islandica (Witbaard and Bergman 2003) demonstrates that autoecological studies should receive the same support as monitoring studies.

Acknowledgements The crew of RV "Pelagia" is acknowledged for their help in collecting the M. truncata. We specially wish to thank Isabel Magalhães (Porto University) for her assistance during field trips and her substantial contribution to the laboratory work. This study was supported by a grant awarded by the Fundação para a Ciência e Tecnologia (Lisbon, Portugal) to Teresa Amaro.

\section{References}

Ballerstedt S (2001) Mya truncata. Blunt gaper. Marine Life Information Network, Marine Biological Association of the United Kingdom, Plymouth http://www.marlin.ac.uk. Cited February 2002

Bergman MJN, van Santbrink JW (1994) A new benthos Dredge ("Triple-D") for quantitative sampling of infauna species of low abundance. Neth J Sea Res 33:129-133

Bisseling CM, van Dam CJFM, Schippers AC, Van der Wielen P, Wiersinga W (2001) Met de Natuur in zee. Rapport expertisecentrum LNV 48

Brousseau D, Baglivo J (1987) A comparative study of age and growth in Mya arenaria (soft-shell clam) from three populations in Long Island Sound. J Shellfish Res 6:17-24

Cook E, Briffa K, Shiyatov S, Mazepa V (1990) Tree ring standardisation and growth trend estimation. In: Cook E, Kairiukstis L (eds) Methods of dendrochronology. Applications in the environmental sciences. Kluwer, Dordrecht, pp 105-108

Cramer A (1991) Benthic metabolic activity at frontal systems in the North Sea. PhD thesis, University of Amsterdam

Creutzberg FC (1985) A persistent chlorophyll a maximum is coinciding with an enriched benthic zone. In: Gibbs PE (ed) Proceedings of the 19th European Marine Biology Symposium, Cambridge University Press, pp 97-108

Creutzberg F, Wapenaar P, Duineveld G, Lopez NL (1984) Distribution and density of the benthic fauna in the southern North Sea in relation to bottom characteristics and hydrographic conditions. Rapp Reun Cons Int Explor Mer 183:101-110

Daan R, Mulder M (2001) The macrobenthic fauna in the Dutch sector of the North Sea in 2000 and a comparison with previous data. NIOZ-Rapport 2001-2

Duineveld GCA, Boon AR (2002) Short-term variations in the fluxes and composition of seston in near-bottom traps in the southern North Sea. Helgol Mar Res 56:140-148

Duineveld GCA, Van Noort GJ (1986) Observations on the population dynamics of Amphiura filiformis, in the Southern North Sea and its exploitation by the dab, Limanda limanda. Neth J Sea Res 20:85-94

Edwards M, Beaugrand G, Reid PC, Rowden AA, Jones MB (2002) Ocean climate anomalies and the ecology of the North Sea. Mar Ecol Prog Ser 239:1-10

Gee A de, Baars MA, van der Veer HW (1991) De Ecologie van het Friese Front. NIOZ-Rapport 1991-2

Hewitt RA, Dale JE (1984) Growth increments of modern Mya truncata L. from the Canadian Arctic, Greenland and Scotland.
Current Research Part B, Geological Survey of Canada 84-1B: 179-186

Jones DS, Arthur MA, Allard DJ (1989) Sclerochronological records of temperature and growth from shells of Mercenaria mercenaria from Narragansett Bay, Rhode Island. Mar Biol 102:225-234

Josefson AB, Conley DJ (1997) Benthic response to a pelagic front. Mar Ecol Prog Ser 147:49-62

Kröncke I, Dippner J, Heyen H, Zeiss B (1998) Long-term changes in macrofaunal communities off Norderney (East Frisia, Germany) in relation to climate variability. Mar Ecol Prog Ser 167:25-36

Lutz RA (1976) Annual growth patterns in the inner shell layer of Mytilus edulis L. J Mar Biol Assoc UK 56:723-731

MacDonald BA, Thomas MLH (1980) Age determination of the soft-shell clam Mya arenaria using shell internal growth lines. Mar Biol 58:105-109

McGill R, Tukey JW, Larsen WA (1978) Variations of Box plots. Am Stat 32:12-16

Metaxas A, Scheibling RE, Young CM (2002) Estimating fertilization success in marine benthic invertebrates: a case study with the tropical sea star Oreaster reticulatus. Mar Ecol Prog Ser 226:87-101

Nakaoka M, Matsui S (1994) Annual variation in the growth rate of Yoldia notabilis (Bivalvia: Nuculanidae) in Otsuchi Bay, northeastern Japan, analyzed using shell microgrowth patterns. Mar Biol 119:397-404

Nilsson HC (1999) Effects of hypoxia and organic enrichment on growth of the brittle stars Amphiura filiformis (O.F. Mueller) and Amphiura chiajei Forbes. J Exp Mar Biol Ecol 237:11-30

O'Connor B, Brower T, Grehan A (1983) Long term assessment of the population dynamics of Amphiura filiformis in Galway Bay. Mar Biol 75:279-286

Richardson CA (2001) Molluscs as archives of environmental change. In: Gibson RN, Barnes M, Atkinson RJA (eds) Oceanography and marine biology: an annual review, vol 39. Taylor \& Francis, London, pp 103-164

Ropes JW (1985) Modern methods used to age oceanic bivalves. Nautilus 99:53-57

Sager G, Sammler R (1983) Mathematical Investigation into longevity of the ocean quahog Arctica islandica (Mollusca: Bivalvia). Int Rev Ges Hydrobiol 68:113-120

Schweingruber FH (1989) Tree rings. Basics and applications of dendrochronology. Kluwer, Dordrecht

Tomczak G, Goedecke E (1964) Die thermische Schichtung der Nordsee auf Grund des mittleren Jahresganges der Temperatur in $1 / 2^{\circ}$ - und $1^{\circ}$-Feldern gever: Hamburg. Dtsch Hydrogr Z [Ergänzungshefte], Ser B 8

Welch HE, Bergmann MA, Siferd TD, Martin KA, Curtis MF, Crawford RE, Conover RJ, Hop H (1992) Energy flow through the marine ecosystem of the Lancaster Sound region, arctic Canada. Arctic 45:343-357

Willmann R (1989) Muscheln und Schnecken der Nord-und Ostsee. Neumann-Neudamm, Melsungen, $310 \mathrm{pp}$

Witbaard R, Bergman M (2003) The distribution and population structure of the bivalve Arctica islandica L. in the North Sea: what possible factors are involved? J Sea Res 340:1-15

Witbaard R, Klein R (1994) Long term trends on the effect of the Southern North Sea beam trawl fishery on the bivalve mollusc Artica islandica L. ICES J Mar Sci 51:99-105

Witbaard R, Duineveld GCA, de Wilde PAWJ (1997) A long-term growth record derived from Arctica islandica (Mollusca, Bivalvia) from the Fladen Ground (northern North Sea). J Mar Biol Assoc UK 77:801-816 